\title{
A Novel UHF RFID Tag Antenna for Cigarette Carton
}

\author{
Rong Yang ${ }^{1}$ and Gang Wang ${ }^{2, *}$ \\ ${ }^{I}$ Department of Telecommunication Engineering, Jiangsu University, Zhenjiang 210013, China \\ ${ }^{2}$ Department of Electronic Engineering and Information Science, University of Science and Technology of China, \\ Hefei 230027, China
}

\begin{abstract}
A novel UHF RFID tag antenna that can be seamlessly integrated into wrapping paper of metallic objects is reported. When designed for printing on cigarette carton with aluminum foil contained, both numerical simulation and measurement indicate that the proposed antenna has input impedance of $(20+j 149) \Omega$ at resonant frequency of $915 \mathrm{MHz}$, which provides satisfactory conjugate match to the Alien Higgs-2 RFID ASIC. The UHF RFID tag with designed antenna on cigarette carton demonstrates $-10 \mathrm{~dB}$ return loss bandwidth of $31 \mathrm{MHz}$ at the $915 \mathrm{MHz}$ UHF RFID band, and a read range of approximately $0.63 \mathrm{~m}$.
\end{abstract}

Keywords: RFID, tag antenna, aluminum foil, cigarette carton.

\section{INTRODUCTION}

In some applications, radio-frequency identification (RFID) tags have to be placed on packages of metallic items or directly on metallic surfaces. The metallic items or metal surface will significantly affect the radiation properties such as impedance match, operation bandwidth and radiation pattern of dipole-like RFID tag antennas. Therefore, specific tag antenna design is generally required for such RFID applications.

In practice, several microstrip patch-type antennas and planar inverted-F (PIF) antennas have been proposed for RFID tag suitable for metallic surface [1-12]. In [4], a slim RFID tag antenna was reported for metallic surface application, but via-holes to the ground plane is needed. In [5-10], RFID tags with PIF-type antennas were reported. The proposed PIF-type antenna either takes a two-layer structure or uses a shorting plate, thus the RFID ASIC can not be mounted in ordinary manner. In [12], a compact slotted PIFtype tag antenna was reported to overcome the problems in previous PIF-type tag antenna.

For cigarette carton applications, it is desired that RFID tags will be printed directly on the wrapping paper with RFID ASIC embedded or attached. In this scenario, the distance between RFID tag antenna and the aluminum foil in cigarette case could be very small (as to $0.05 \mathrm{~mm}$ here in our design consideration), which issues a big challenge in the RFID tag design, especially if we want to design a small RFID tag. To realize the inductance required for the tag, large metal parts in the RFID tag is generally required. In [13], an RFID tag on cigarette carton of dimensions of $271 \times 84 \mathrm{~mm}^{2}$ was reported and tested, where a large ground plane of dimensions of approximately $178 \times 87 \mathrm{~mm}^{2}$ is

*Address correspondence to this author at the Department of Electronic Engineering and Information Science, University of Science and Technology of China, Hefei 230027, China; Tel: 86-0551-3607520;

Fax: 86-0551-3607520; E-mails: gwang01@ustc.edu.cn, yrever@gmail.com included and folded around the end side of the cigarette carton, and the radiating patch and the ground plane are on two opposite sides of the carton.

In this Letter, a novel UHF RFID tag for cigarette carton is proposed and designed. Our RFID tag is designed to have dimensions of approximately $160 \times 66.5 \mathrm{~mm}^{2}$, and is printed on one side of the cigarette carton. The actual distance between the RFID tag antenna and aluminum foil is only $0.05 \mathrm{~mm}$. The tag antenna is demonstrated to have $-10 \mathrm{~dB}$ return loss bandwidth of $31 \mathrm{MHz}$ at the $915 \mathrm{MHz}$ UHF RFID band, and a read range of approximately $0.63 \mathrm{~m}$.

\section{TAG ANTENNA DESIGN}

Structure and geometric parameters of the proposed UHF RFID tag antenna printed on the cigarette carton is shown in Fig. (1). As shown in Fig. (1a), the proposed tag is designed and printed on one side of a cigarette carton, different from the folded patch-type tag antenna in [13].

Fig. (1b) shows the structure of the proposed tag. In tag, there is a gap left on the antenna structure for RFID ASIC installation. The tag antenna is designed to fit the Alien Higgs-2 IC, which has input impedance of $(15-j 145) \Omega$ at $915 \mathrm{MHz}$. At operating frequency of $915 \mathrm{MHz}$, the antenna has dimensions of approximately $\mathrm{L} \times \mathrm{W}=160 \times 66.5 \mathrm{~mm}^{2}$, which takes a relatively small size. In the simulation and optimization, the conductive ink is supposed to have conductivity of $5 \times 10^{6} \mathrm{~S} / \mathrm{m}$ and thickness of $0.03 \mathrm{~mm}$ [14], and the carton paper is supposed to have dielectric constant of $\varepsilon_{r}=2$, dielectric loss tangent of $\tan \delta=0.04$ and thickness of $0.52 \mathrm{~mm}$. The proposed antenna parameters are given in Table. 1. The gap indicated in Fig. (1b) for RFID ASIC is $1 \mathrm{~mm}$.

\section{PERFORMANCE OF THE PROPOSED TAG ANTENNA}

In RFID tag antenna design, one of the major challenges is to realize conjugate match between the antenna and the 


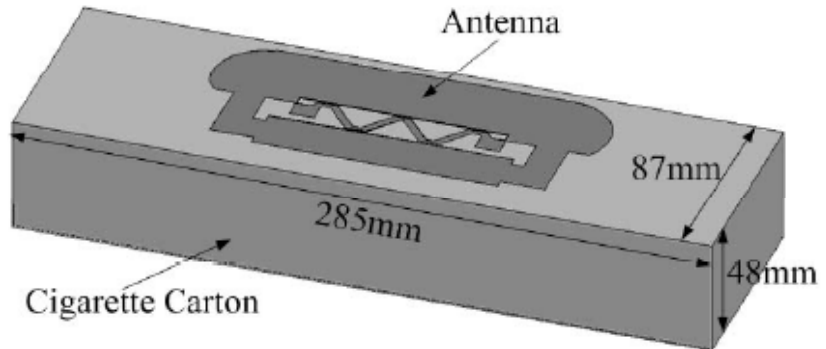

(a). The tag antenna integrated on the cigarette carton.

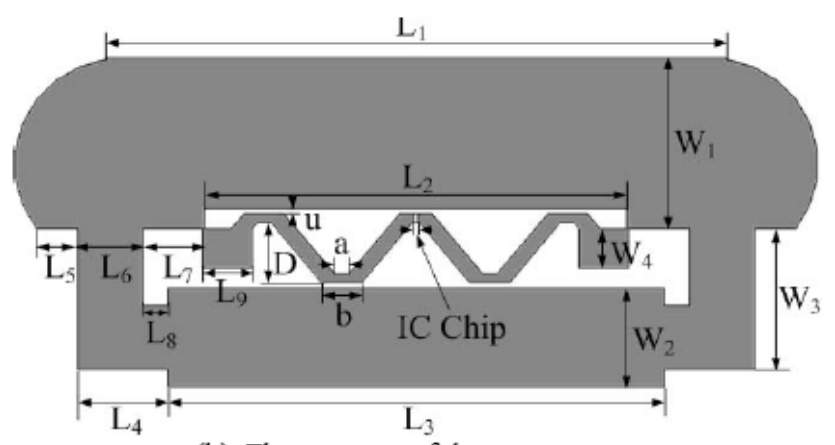

(b). The structure of the tag antenna.

Fig. (1). Structure and dimensions of cigarette carton and the tag antenna.

Table 1. Antenna Parameters

\begin{tabular}{|c|c|c|c|}
\hline L1 (mm) & $\mathbf{1 2 5}$ & L9 $(\mathbf{m m})$ & $\mathbf{1 0}$ \\
\hline \hline L2 $(\mathrm{mm})$ & 85 & $\mathrm{~W} 1(\mathrm{~mm})$ & 36 \\
\hline L3 $(\mathrm{mm})$ & 100 & $\mathrm{~W} 2(\mathrm{~mm})$ & 20 \\
\hline L4 $(\mathrm{mm})$ & 18 & $\mathrm{~W} 3(\mathrm{~mm})$ & 28.5 \\
\hline L5 $(\mathrm{mm})$ & 8.3 & $\mathrm{~W} 4(\mathrm{~mm})$ & 8 \\
\hline L6 $(\mathrm{mm})$ & 18 & $\mathrm{D}(\mathrm{mm})$ & 12 \\
\hline L7 $(\mathrm{mm})$ & 12.2 & $\mathrm{a}(\mathrm{mm})$ & 3 \\
\hline L8 $(\mathrm{mm})$ & 5 & $\mathrm{~b}(\mathrm{~mm})$ & 8 \\
\hline
\end{tabular}

RFID ASIC. The proposed tag antenna shown in Fig. (1) is fabricated and tested on a cigarette carton. Fig. (2) shows the tag on cigarette carton under test.

To measure the input impedance of the tag antenna, we follow the method and procedure proposed in [15] by using a two-port VNA and a test fixture. The test fixture is constructed by using two semi-ridge coaxial cables with a length of $100 \mathrm{~mm}$. The coaxial cables are soldered together on their outer conductors. One end of the fixture with SMA connector is connected to the VNA through the test cables.

Fig. (3) shows the measured and simulated input impedance of the proposed antenna when it is integrated on a cigarette carton with foils. The resistance of the antenna shows good agreement with the simulation results. However, a frequency shift of is observed for the reactance of the antenna. In addition, the measured resistance and reactance of the impedance are with smaller amplitude than simulated ones. The differences between simulation results and measurement

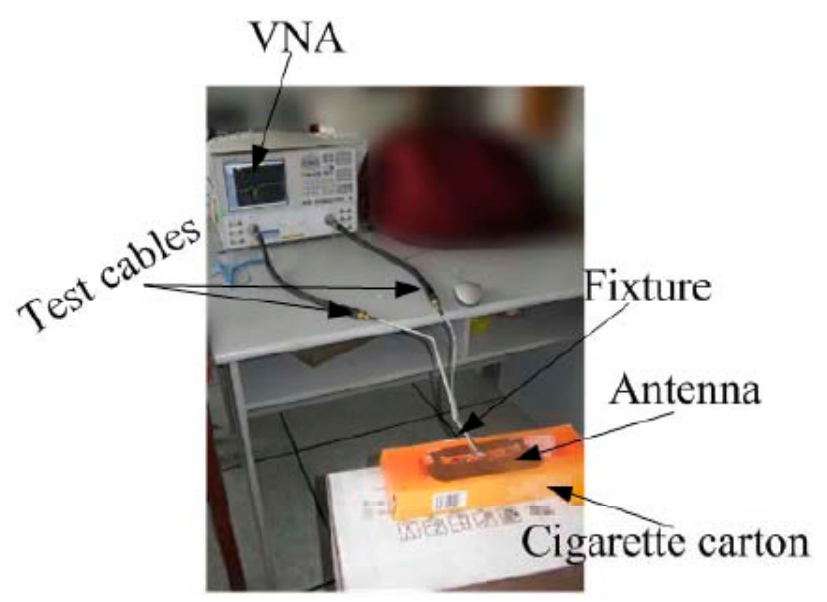

Fig. (2). Measurement setup using Agilent network analyzer.

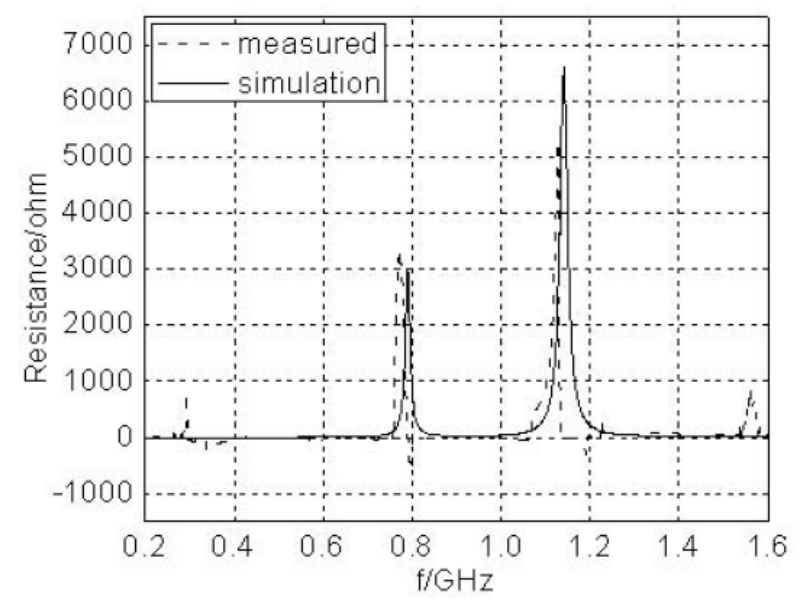

(a). Resistance.

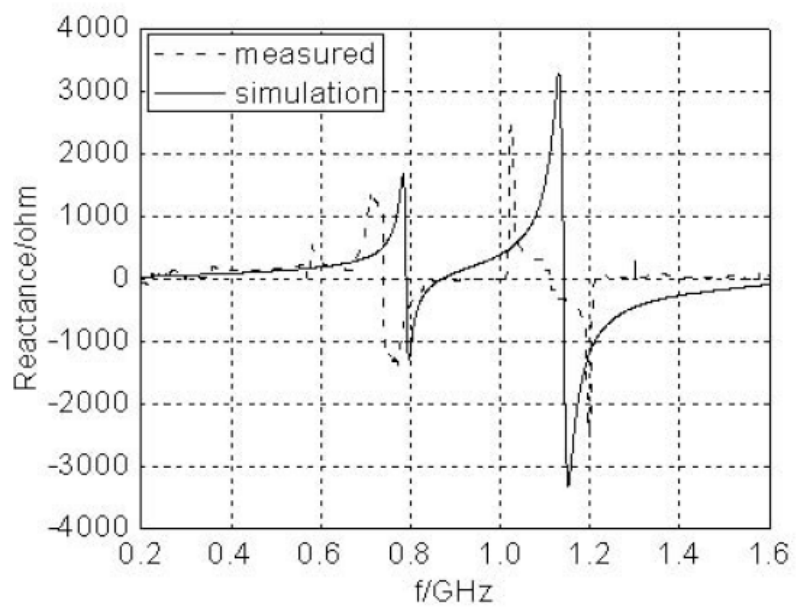

(b). Reactance.

Fig. (3). Measuered and simulated input impedance of the proposed tag antenna.

may be caused by the measurement probe placed above the antenna and by the distortion at antenna input port occurred when connected to the test fixture.

At $915 \mathrm{MHz}$, the impedance of the antenna on cigarette carton is measured to be $(20+j 149) \Omega$. The Alien Higgs- 2 IC has input impedance of $(15-j 145) \Omega$ at $915 \mathrm{MHz}$. There- 


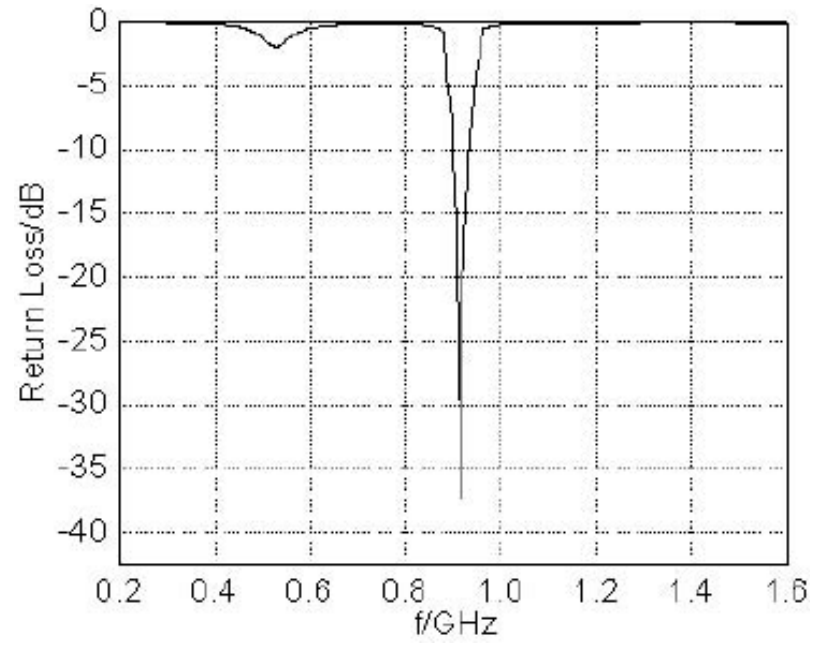

Fig. (4). Return loss of the proposed tag antenna.

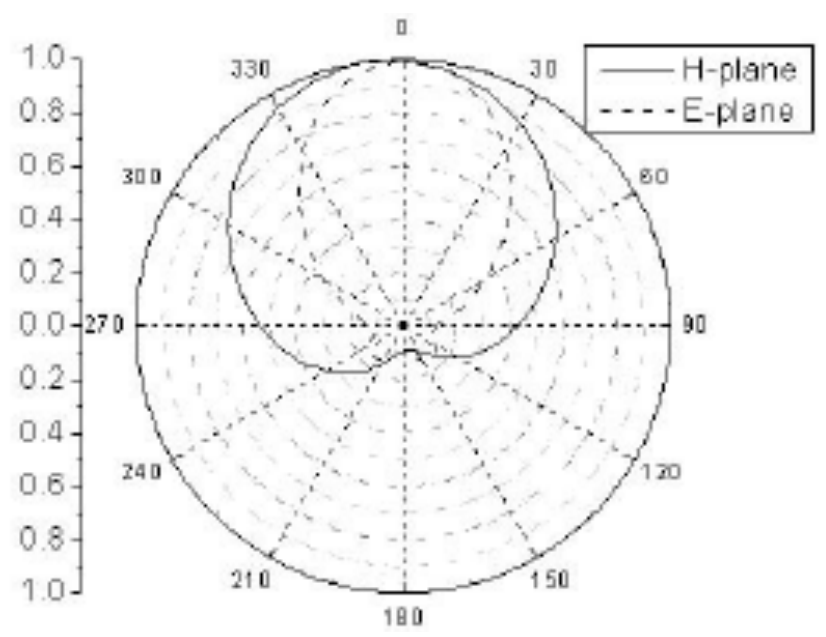

Fig. (5). Radiation pattern of the proposed tag antenna.

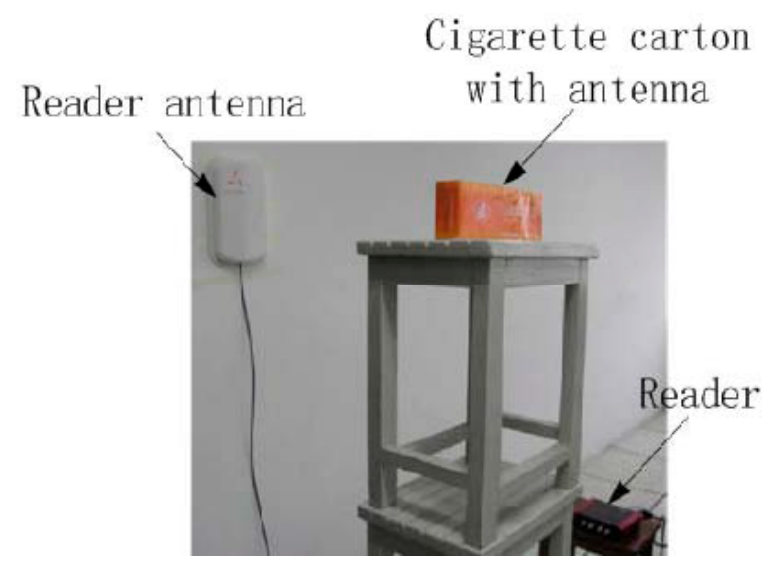

Fig. (6). Measurement setup using ALR-9800 Enterprise RFID Reader.

fore, acceptable conjugate match between the design tag antenna and the Alien Higgs-2 microchip can be achieved in our design.

Fig. (4) shows simulated return loss of the proposed tag antenna, where we measured a bandwidth of $31 \mathrm{MHz}$ at the $915 \mathrm{MHz}$ UHF RFID band, ranging from $902 \mathrm{MHz}$ to
933MHz. Therefore, the proposed carton tag antenna meets the $26 \mathrm{MHz}$ bandwidth requirement.

The simulated radiation pattern of the tag antenna mounted on the cigarette carton is given in Fig. (5). From Fig. (5), a desired radiation pattern for RFID reader deployed above the cigarette carton is observed. The antenna has a gain of $2.5 \mathrm{dBi}$.

Fig. (6) shows the measurement setup using ALR-9800 RFID Reader. The proposed antenna is set on a cigarette carton, and the read range distance is $63 \mathrm{~mm}$.

\section{CONCLUSION}

A new $915 \mathrm{MHz}$ RFID tag antenna that can be printed on cigarette carton is proposed. The designed tag antenna has been proven to function well if integrated seamlessly into a package containing conductive foil. Due to the close proximity to metallic foil, the size of the tag antenna is relatively large. Future work will aim at design with size reduction.

\section{ACKNOWLEDGEMENTS}

This work has been supported in part by Ministry of Science and Technology of China under grant 2009GJC10042.

\section{REFERENCES}

[1] L. Ukkonen, L. Sydanheimo, and M. Kivikoski, "Effects of metallic plate size on the performance of microstrip patch-type tag antennas for passive RFID”, IEEE Antennas Wireless Propag. Lett. vol. 4, no. 5, pp. 410-413, 2005.

[2] J. S. Kim, W. C. Choi, G. Y. Choi, C. S. Pyo, and J. S. Chae, "Shorted microstrip patch antenna using inductively coupled feed for UHF RFID tag", ETRI J., vol. 30, no. 4, pp. 600-602, 2008.

[3] B. Yu, S. J. Kim, B. Jung, F. J. Harackiewicz, and B. Lee, "RFID tag antenna using two-shorted microstrip patches mountable on metallic objects", IEEE Microw. Opt. Technol Lett., vol. 49, no. 2, pp. 414-416, 2007.

[4] S. L. Chen, "A miniature RFID tag antenna design for metallic objects application", IEEE Antennas Wireless Propag. Lett., vol. 8, pp. 1043-1045, 2009.

[5] S. L. Chen and K. H. Lin, "A slim RFID tag antenna design for metallic object applications", IEEE Antennas Wireless Propag. Lett., vol. 7, pp. 729-732, 2008.

[6] S. Lauri, U. Leena, and K. Markku, "Effects of size and shape of metallic objects on performance of passive radio frequency identification", Int. J. Adv Manuf. Technol., vol. 30, no. 9, pp. 897-905, 2006.

[7] G. Marrocco, "The art of UHF RFID antenna design: Impedance matching and size-reduction techniques", IEEE Antennas Propag. Mag., vol. 50, no.1, pp. 66-79, 2008.

[8] H. Mervi, J. Kaarle, P. Pekka, and S. Jussi, "Dual-band platform tolerant antennas for radio-frequency identification", IEEE Trans. Antennas Propag., vol. 54, no. 9, pp. 2632-2637, 2006.

[9] H. Mervi, K. Kaarle, and S. Jussi, "Triple-band PIFA for radio frequency identification", Electron. Lett., vol. 42, no. 17 pp. 958 960, 2006.

[10] H. W. Son and G. Y. Choi, "Orthogonally proximity-coupled patch antenna for a passive RFID tag on metallic surfaces", IEEE Microw. Opt. Technol. Lett., vol. 49, no. 3, pp. 715-717, 2007.

[11] W. Choi, H. W. Son, J. H. Bae, G. Y. Choi, C. S. Pyo, and J. S. Chae, "An RFID tag using a planar inverted-F antenna capable of being stuck to metallic objects", ETRI J., vol. 28, no. 2, pp. 216$218,2006$.

[12] H. Kwon, and B. Lee, "Compact slotted planar inverted-F RFID tag mountable on metallic objects", Electron. Lett., vol. 41, no. 24, pp. 1308-1310, 2005.

[13] L. Ukonen, M. Schaffrath, D. W. Engels, L. Sydanheimo, and M. Kivikoski, "Operability of folded microstrip patch-type tag antenna in the UHF RFID bands within 865-928 MHz", IEEE Antennas Wireless Propag. Lett., vol. 5, no. 1, pp. 414-417, 2006. 
[14] L. Yang, A. Rida, R. Vyas, and M. M. Tentzeris, "RFID tag and RF structures on a paper substrate using inkjet-printing technology", IEEE Trans. Microw. Theor. Tech., vol. 55, no. 12, pp. 2894-2901, 2007.
[15] X. M. Qing, C. K. Goh, and Z. N. Chen, "Impedance characterization of RFID tag antennas and application in tag Co-Design", IEEE Ttrans. Microw. Theor. Tech., vol. 57, no. 5, pp. 1268-1274, 2009.

Received: March 01, 2011

Revised: April 18, 2011

Accepted: May 02, 2011

(C) Yang and Wang; Licensee Bentham Open.

This is an open access article licensed under the terms of the Creative Commons Attribution Non-Commercial License (http://creativecommons.org/licenses/by-nc/3.0/) which permits unrestricted, non-commercial use, distribution and reproduction in any medium, provided the work is properly cited. 